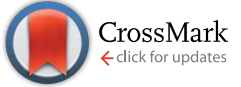

Cite this: RSC Adv., 2017, 7, 2033

Received 2nd November 2016 Accepted 11th December 2016

DOI: 10.1039/c6ra26180a

www.rsc.org/advances

\section{Recognition of the key chemical constituents of sewage sludge for biogas production $\uparrow$}

\begin{abstract}
Xiaohu Dai, + Ying Xu, ${ }^{*}$ Yiqing Lu and Bin Dong*
One of the key factors hindering the application of anaerobic sludge digestion is the lower biogas production (BP). In this paper, the main constituents of sewage sludge (SS) and model sludge (MS) were reconsidered and a biochemical methane potential assay of sludge was conducted with the effect of different key chemical constituents. It was found that the humic matter, metal ions (such as Fe, Ca, and $\mathrm{Al}$ ), silts were the main differences of constituents between SS and MS, and the interactions between them and easily biodegradable organic matter (EBOM) were the main factors for limiting the BP. Further research indicates that the apparent activated energy of sludge organic solubilisation could be used to suggest the strength of the interactions between non-biodegradable matter and EBOM, and the biodegradability of the EBOM in sludge particulate can be indicated by surface site density. This study can provide a new path for enhancing the BP per unit of organic matter and enlighten environmental scientists to develop more effective methods for improving the anaerobic sludge digestion.
\end{abstract}

\section{Introduction}

As a byproduct of biological wastewater treatment, large amounts of organic waste are inevitably produced in the SS. If they are not treated and disposed of appropriately, it will cause severe secondary pollution. ${ }^{1}$ So, how to dispose of the massive $\mathrm{SS}$ is an intractable problem. Anaerobic digestion, which can generate renewable energy (such as methane) from the organic waste, is one of the attractive methods for treating the large amounts of SS. It can reduce the amount of sludge, kill the pathogenic microorganisms, and produce biogas., ${ }^{2,3}$

One of the main objectives for the anaerobic digestion of SS is enhancing the MP, especially the MP per unit of organic matter. In principle, there are three main parameters that influence the MP. Operational conditions of the digester, pretreatment methods of sludge, and the characteristics of sludge. Most of the researches have focused on the first two. Several operational factors, such as sludge feed, retention times, temperature, alkalinity, high-solid, co-digestion, mechanical agitation, and types of anaerobic digestion etc., have been reported to affect the MP. ${ }^{4-7}$ Since that the hydrolysis of sludge organic matter is the rate-limiting step in the anaerobic digestion process was recognized, ${ }^{8}$ large amounts of pretreatment methods have been studied to improve the MP,

State Key Laboratory of Pollution Control and Resource Reuse, School of Environmental Science and Engineering, Tongji University, Shanghai, 200092, China.E-mail: assassinxu@tongji.edu.cn; tj_dongbin@163.com

$\dagger$ Electronic supplementary information (ESI) available. See DOI: 10.1039/c6ra26180a

\$ Ying Xu and Xiaohu Dai contributed to the work equally and should be regarded as co-first authors. such as ultrasonic treatment, alkaline treatment, microwaveacid treatment, thermo-chemical treatment, and even the high pressure treatment etc. ${ }^{9-16}$ Although these pretreatment methods are effective for improving the performance of anaerobic digestion in some degree, amounts of phenomena can not be reasonably explained. The optimum conditions and magnitude of the improvement vary considerably. ${ }^{2}$ Some pretreatment methods can improve the biodegradability of sludge, while others only can accelerate the rate of solubilisation of sludge organic matter. ${ }^{17}$ Besides, the same pretreatment method also can bring different results. For example, thermal treatment can increase the solubilization of sludge organic matter, it is not necessarily improve the biogas production. ${ }^{\mathbf{1 8 , 1 9}}$ In fact, both of the operational parameters and pretreatment methods are the external measures for improving the anaerobic sludge digestion, which are usually depended on the characteristics of sludge. Characteristics are determined by structure, and sludge is no exception. The key chemical constituent, which can interact with each other, is one of the most important factors for the structure of sludge. Essentially, the performance of anaerobic digestion is determined by the key chemical constituents of sludge. To be exact, the mode of occurrence of the EBOM in sludge is the key factor for the MP per unit of organic matter. For example, although both of kitchen waste and SS have the same main organic compounds such as protein, carbohydrates, and lipid etc., kitchen waste has a higher MP per unit of organic matter than that of SS at the same operational conditions of anaerobic digestion. ${ }^{20}$ One of the reasonable explanations is that the mode of occurrence of the EBOM in sludge is different from that in kitchen waste. There are many inorganic matters (such as metal ions and silica) and NBOM (such as humic 
matter) in sludge, and they could interact with the EBOM. In other words, the EBOM is not independent in sludge. What the main NBM are and how these constituents affect the anaerobic digestion of EBOM. No one studied before.

In this paper, we proposed a new hypothesis that the SS is mainly composed of the EBOM, NBOM, M, and Silica and their interactions were the key factors for limiting the biogas production per unit of organic matter in anaerobic digestion process. The main constituents of SS and MS were first analyzed, and the key chemical constituents of SS were reconsidered. A 30 day BMP assay of sludge was carried out with the effect of different key chemical constituents. Then, the AAE of sludge organic solubilisation and SSD of sludge particulate were measured. Finally, the correlations between NCMP, AAE, and SSD were explored. Base on this recognition, a new research path for enhancing the biogas production of SS was provided.

\section{Materials and methods}

\subsection{Characteristics of sludge}

SS was collected from Quyang municipal wastewater treatment plants (Shanghai, China) and stored at $4{ }^{\circ} \mathrm{C}$ until its utilization. MS was from a 25 day sequencing batch reactor (SBR) using synthetic wastewater. Basic constituents of the synthetic wastewater were listed in the Table S1 (ESI $\dagger$ ). The main characteristics and constituents of SS and MS were summarized in the Table 1 .

\subsection{Sample preprocessing and biogas production tests}

Micron-sized silica particles (the detail information was in Text S1 $\left(\mathrm{ESI} \dagger\right.$ )), analytical-grade $\mathrm{FeCl}_{3}$ (Sinopharm Chemical Reagent Co., Ltd, China), and analytical-grade HM (humic acid, sodium salt; Aladdin Reagents Co., Ltd) were used to simulate the grits, metal ions, and non-biodegradable organic matters in SS, respectively. Eight sets of sample processing were conducted simultaneously at room temperature and the samples were named as MS, MS-M, MSSilica, MS-HM, MS-HM-M, MS-HM-Silica, MS-HM-M-Silica, and SS, respectively. MS and SS were defined as control groups and the other samples with different additions were originated from the
MS. The percentages of additions (Fe ions, HM, and Silica) were consistent with those in the SS. For example, the mass percent of metal in SS is about 3.5\% TS and the same percentage of Fe ions were in the MS-M sample. For the MS-M sample, $200 \mathrm{~g}$ MS and $0.25 \mathrm{~g} \mathrm{FeCl}_{3}$ were mixed in a $500 \mathrm{~mL}$ beaker and stirred at $150 \mathrm{rpm}$ for $24 \mathrm{~h}$ by a magnetic stirrer.

BMP assay was carried out at mesophilic temperature conditions $\left(37^{\circ} \mathrm{C}\right)$ to measure the methane yield of the sludge samples (MS, MS-M, MS-Silica, MS-HM, MS-HM-M, MS-HM-Silica, MSHM-M-Silica, and SS) and the basic parameters of these sludges and seed sludge were summarized in the Table S2 (ESI $\dagger$ ). In the BMP tests, the inoculum-to-substrate ratio was set to $1: 2$ (calculated with VS). Before the start-up of tests, $\mathrm{pH}$ of all samples were carefully checked and neutralized to around 7.0. $600 \mathrm{~mL}$ bottles with $400 \mathrm{~mL}$ of working volume were used. Bottles containing only inoculum were used as blank tests, which were named MS-Control (100 $\mathrm{g}$ seed sludge) and SS-Control (137 $\mathrm{g}$ seed sludge), respectively. The volume of biogas produced during the running test was measured periodically. MP from only the inoculum was subtracted from total methane production.

\subsection{Solubilisation property of sludge}

The rate of sludge organic solubilisation was measured. In this test, each beaker, containing $200 \mathrm{~g}$ of sludge and $200 \mathrm{~g}$ of deionized water, was heated in water baths at the different controlled temperatures of $35^{\circ} \mathrm{C}, 45^{\circ} \mathrm{C}$, and $55^{\circ} \mathrm{C}$ for 34 hours, respectively. The beakers were covered with lids to prevent water evaporation and magnetically stirred to ensure temperature homogeneity. Around $2 \mathrm{~mL}$ samples each were taken from the beakers at the determined time $(0 \mathrm{~h}, 1 \mathrm{~h}, 2 \mathrm{~h}, 3 \mathrm{~h} \ldots 12 \mathrm{~h}, 24 \mathrm{~h}$, $26 \mathrm{~h}, 28 \mathrm{~h}, 30,32 \mathrm{~h}, 34 \mathrm{~h}$ ) and rapid cooling. Then, the samples were centrifuged at $15000 \mathrm{rpm}$ for 15 minutes to separate solids from the solution. The supernatant was collected and total organic carbon (TOC) of the supernatant was determined by a TOC analyzer (SHIMADZU, TOC-L CPH/CPN).

\subsection{Analytical methods}

The surface site of sludge, which was treated as proton binding sites, can be measured by acid-base titration according to the

Table 1 Basic characteristics and main components of SS and $\mathrm{MS}^{a}$

\begin{tabular}{|c|c|c|c|}
\hline & SS & MS & RAV (SS/MS) \\
\hline VS (\% TS) & $72.3 \pm 1.5$ & $90.2 \pm 2.1$ & 0.80 \\
\hline TS (\%) & $4.1 \pm 0.2$ & $1.2 \pm 0.3$ & 3.42 \\
\hline Humic matter ( $\left.\mathrm{mg} \mathrm{g}^{-1} \mathrm{VS}\right)$ & $148 \pm 17$ & $10 \pm 2$ & 14.8 \\
\hline Carbohydrates (mg eq. Gluc per g vS) & $117 \pm 11$ & $185 \pm 21$ & 0.63 \\
\hline Lipids ( $\left.\mathrm{mg} \mathrm{g}^{-1} \mathrm{VS}\right)$ & $35 \pm 8$ & $32 \pm 3$ & 1.09 \\
\hline Silt content $\left(\mathrm{mg} \mathrm{g}^{-1} \mathrm{DS}\right)$ & $204 \pm 10$ & ND & - \\
\hline $\mathrm{Ca}\left(\mathrm{mg} \mathrm{g}^{-1} \mathrm{DS}\right)$ & $9 \pm 5$ & $0.4 \pm 0.1$ & 22.5 \\
\hline $\mathrm{Fe}\left(\mathrm{mg} \mathrm{g}^{-1} \mathrm{DS}\right)$ & $16 \pm 8$ & $1.0 \pm 0.5$ & 16.0 \\
\hline $\mathrm{Al}\left(\mathrm{mg} \mathrm{g}^{-1} \mathrm{DS}\right)$ & $10 \pm 7$ & ND & - \\
\hline
\end{tabular}

${ }^{a}$ TS: total solids; VS: volatile solids; DS: dry solid; TCOD: total chemical demand oxygen; ND: not detected. 
method from Wang etc. ${ }^{21}$ TS, VS/TS, TCOD, Total Kjeldahl Nitrogen (TKN), ammonia $\left(\mathrm{N}^{-\mathrm{NH}_{4}}{ }^{+}\right), \mathrm{Ca}, \mathrm{Fe}$, and $\mathrm{Al}$ of the sludge were determined according to standard methods. ${ }^{22} \mathrm{HM}$ content was calculated according to the standard isolation protocol from the International Humic Substance Society (IHSS). ${ }^{23,24}$ Protein content was calculated based on the assumption that the protein contains $16 \%(\mathrm{w} / \mathrm{w})$ nitrogen and taking into account TKN and $\mathrm{N}-\mathrm{NH}_{4}{ }^{+}$measurements. ${ }^{25}$ Carbohydrates and lipids contents were determined by Anthrone method ${ }^{26}$ and Soxhlet extraction, ${ }^{27}$ respectively. Silt content of sludge was measured by DWA German Association for Water. ${ }^{28} \mathrm{CH}_{4}$ content of the biogas was determined by a gas chromatograph (GC, Agilent Technologies, 6890N, USA).

\section{Results and discussion}

\subsection{Analyses of the sludge properties}

Table 1 shows the basic characteristics and main components of SS and MS. The RAVs of HM and main metal ions (M) between SS and MS (about 14.8 and 25.0 respectively) were larger than others, and the silt (Silica) content in the MS was not detected. These results indicate that the main differences on the components between SS and MS were HM, M, and Silica. It is well known to all that the protein, carbohydrates, and lipids were all the EBOM, and they can be converted into biogas easily in anaerobic digestion process. ${ }^{29}$ However, the complexation reaction between $\mathrm{EBOM}$ and $\mathrm{M}$, adsorption reaction between EBOM and Silica, and cross-linked action between EBOM and HM could occur in sludge. With the effect of HM, M, and Silica it was debatable whether or not the EBOM can be easily converted into biogas.

\subsection{Effect of HM, M, and silica on the NCMP, AAE, and SSD}

The cumulative methane yields in terms of $\mathrm{mL} \mathrm{CH}_{4}$ for different sludge samples were present in the Fig. S1 (ESI $\dagger$ ), and the NCMP, AAE, and SSD for different sludge samples were calculated as shown in Fig. 1. NCMP of MS was higher than that of the SS at the same conditions, indicating that organic matter in MS was biodegraded more easily than in SS in anaerobic

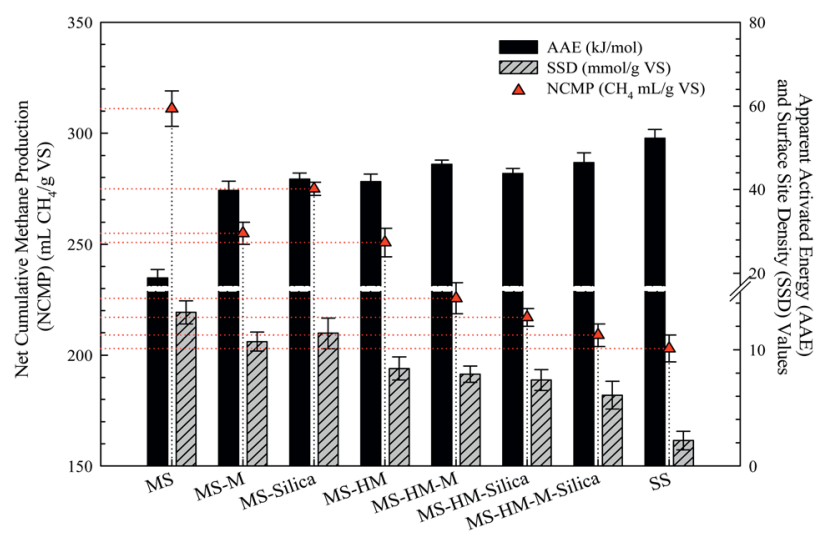

Fig. 1 NCMP, AAE values of organic solubilisation and SSD values for different sludge samples. digestion process. In addition, the NCMP of MS was decreased with the effect of HM, M, and Silica, which suggest that all NBM can inhibit biogas production of the EBOM. One of the reasonable explanations is that these matters can interact with the EBOM and thus restricting the biodegradation of EBOM. The detailed influence mechanisms of the NBM will be discussed in the successive researches. Fundamentally, revealing these mechanisms can make it possible to improve the MP per unit of organic matter in the SS.

AAE of sludge organic solubilisation was measured to characterize the abilities of organic solubilisations of the different sludge samples. The ability of sludge organic solubilisation was determined by the interactions between organic matter and NBM in sludge, and thus AAE can reflect the strength of their interactions. AAE can be calculated by the Arrhenius equation ${ }^{30}$ and the Arrhenius plots of different sludge samples were summarized in the Fig. S2 (ESI $\dagger$ ). As is shown in Fig. 1, MS has a lower AAE value than that of SS, indicating that less interactions between organic matter and NBM in MS than in SS. In addition, the derivates of MS (such as MS-M, MS-Silica etc.) also have a higher AAE value than MS. This indicates that the HM, M, and Silica can interact with the organic matter in MS and restrict the organic solubilisation. Especially, the AAE value of MS-HM-M-Silica was the highest in the derivates of MS and both of the MS-HM-Silica and MS-HM-M have a higher AAE value than the MS-M, MS-HM, and MS-Silica, indicating that the AAE value increased with the increase of NBM. This is mainly attributed to the enhancement of the interactions.

For enzymes, the surface of the active site is lined with amino acid residues with substituent groups and that have a good affinity with the carboxyl groups. ${ }^{31}$ The surface site of sludge particulate was treated as a weak monoprotic acid (such as $-\mathrm{COOH}$ ) or proton binding site (such as - $\mathrm{COO}-$ ). It is reasonable that some of these surface sites have potential to be the binding sites for the extracellular enzyme (such as hydrolases) in anaerobic digestion process. The more surface sites, the more chances for the hydrolases to bind to the organic matter of sludge particulates can be obtained. It means that the SSD of sludge could be an important index for the biodegradation of organic matter in sludge particulates. In the Fig. 1, the SSD value of MS was about 6 times that of the SS, suggesting that more organic matter in the MS particulates could be biodegradable than in the SS. With the effect of HM, M, and Silica the SSD value of MS was reduced, and the SSD value of MS-HM-MSilica was the minimum with the exception of SS attributing to the combined effect of HM, M, and Silica. These results indicate that the NBM can interact with the organic matter of sludge particulate by the surface site, and the combined effect is more serious. However, it is a worthy task of what the specific interactions between the NBM and the EBOM are, and how to release the binding EBOM by destroying the interactions.

\subsection{Correlation analyses among the NCMP, AAE and SSD}

The relationships between AAE, NCMP, and SSD for different sludge samples were summarized in Fig. 2. As is shown in the Fig. 2(a), with increased SSD values a downward trend in the 
AAE values of different sludge samples was presented, indicating that increasing the SSD of sludge particulate can facilitate the organic solubilisation at the same VS condition. It also suggests that with higher SSD values more organic matters of sludge particulates are likely to be converted into biogas in the anaerobic digestion process. With the exception of MS sample there was a negative linear correlation between the AAE and SSD $\left(R^{2}=0.844\right)$ values for the other sludge samples (Fig. 2(a)), which indicate that the characteristic of organic solubilisation of simulated sludge sample with introduction of the HM, M, and Silica is close to that of SS. It also implies that the main factors for restricting the organic solubilisation of SS were the HM, M, and Silica. At the same VS condition, the NCMP increases with the increase of SSD for all the sludge samples (Fig. 2(b)). This result also verifies the above-mentioned suggestion that the biogas production per unit of organic matter will increase with the increase of SSD, and it provides a new research path for improving the biogas production. Moreover, an obvious positive correlation between the NCMP and SSD for the sludge samples except for the SS was present in the Fig. 2(b), which is probably attributed to the same EBOM in these sludge samples. This result indicates that with the introduction of HM, M, and Silica the biodegradability of EBOM in different sludge samples was different, suggesting that SSD can

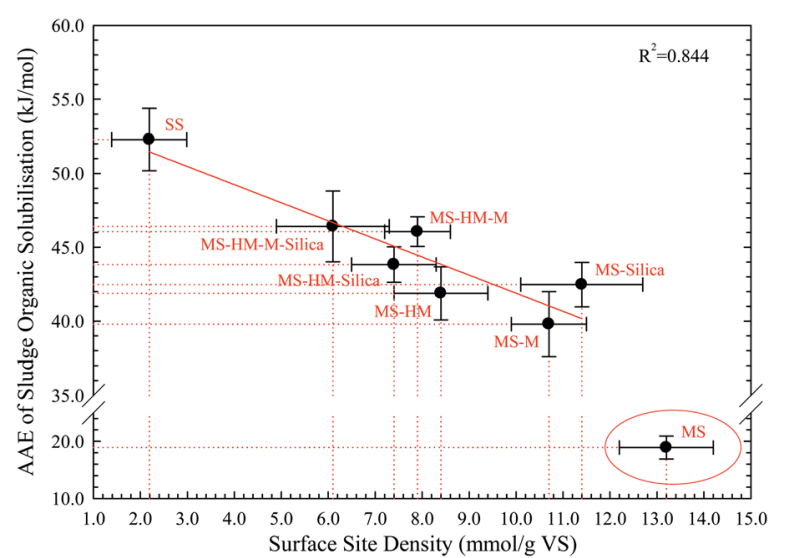

(a)

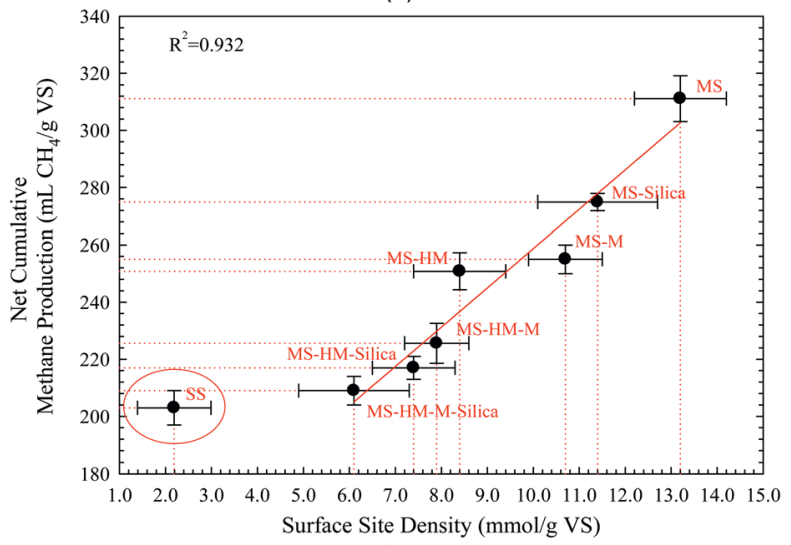

(b)

Fig. 2 Relationships between the AAE, NCMP, and SSD for different sludge samples: (a) the relationship between the AAE and SSD; (b) the relationship between the NCMP and SSD. be used as an index for the biodegradability of organic matter of sludge particulate. And this can provide an important index for studying the interactions between the EBOM and NBM. Although the new hypothesis that SS is mainly composed of EBOM, HM, M, and Silica and their interactions are fundamentally responsible for the lower biogas production was preliminarily confirmed and the key chemical constituents of SS were proposed, the interaction mechanisms between them and EBOM should be further researched.

\section{Abbreviations}

$\begin{array}{ll}\text { SS } & \text { sewage sludge } \\ \text { MP } & \text { methane production } \\ \text { EBOM } & \text { easy biodegradable organic matter } \\ \text { NBOM } & \text { non-biodegradable organic matter } \\ \text { NBM } & \text { non-biodegradable matter } \\ \text { M } & \text { metal ions } \\ \text { Silica } & \text { micron-sized silica particle } \\ \text { MS } & \text { model sludge } \\ \text { BMP } & \text { biochemical methane potential } \\ \text { AAE } & \text { apparent activated energy } \\ \text { SSD } & \text { surface site density } \\ \text { NCMP } & \text { net cumulative methane production } \\ \text { TS } & \text { total solids } \\ \text { VS } & \text { volatile solids } \\ \text { RAVs } & \text { ratio of average values between SS and MS }\end{array}$

\section{Acknowledgements}

This study was financially supported by the National Natural Science Foundation of China (NSFC) (Grants 51578397 and 51538008).

\section{References}

1 D. B. Wang, J. W. Zhao, G. M. Zeng, Y. G. Chen, P. L. Bond and X. M. Li, Environ. Sci. Technol., 2015, 49, 12253-12262.

2 L. Appels, J. Baeyens, J. Degrève and R. Dewil, Prog. Energy Combust. Sci., 2008, 34, 755-781.

3 H. Carrère, C. Dumas, A. Battimelli, D. J. Batstone, J. P. Delgenès, J. P. Steyer and I. Ferrer, J. Hazard. Mater., 2010, 183, 1-15.

4 H. G. Michael, The Microbiology of Anaerobic Digesters, John Wiley \& Sons, Inc., New Jersey, 2003.

5 N. N. Duan, B. Dong, B. Wu and X. H. Dai, Bioresour. Technol., 2012, 104, 150-156.

6 M. Tandukar and S. G. Pavlostathis, Water Res., 2015, 87, 432-445.

7 X. C. Liao and H. Li, Appl. Energy, 2015, 148, 252-259.

8 D. Bolzonella, P. Pavan, M. Zanette and F. Cecchi, Ind. Eng. Chem. Res., 2007, 46, 6650-6655.

9 C. P. Chu, D. J. Lee, B. V. Chang, C. S. You and J. H. Tay, Water Res., 2002, 26, 2681-2688.

10 D. Zhang, Y. G. Chen, Y. C. Zhao and Z. X. Ye, Environ. Sci. Technol., 2011, 45, 803-808. 
11 D. H. Kim, E. Jeong, S. E. Oh and H. S. Shin, Water Res., 2010, 44, 3093-3100.

12 G. Y. Zhen, X. Q. Lu, Y. Y. Li and Y. C. Zhao, Appl. Energy, 2014, 128, 93-102.

13 P. J. Strong, B. McDonald and D. J. Gapes, Bioresour. Technol., 2011, 102, 5520-5527.

14 S. N. Mehdizadeh, C. Eskicioglu and J. Bobowski, Water Res., 2013, 47, 5040-5051.

15 A. K. Wahidunnabi and C. Eskicioglu, Water Res., 2014, 66, 430-446.

16 A. Cesaro and V. Belgiorno, Chem. Eng. J., 2014, 240, 24-37.

17 M. Carlsson, A. Lagerkvist and M. S. Fernando, Waste Manage., 2012, 32, 1634-1650.

18 N. Hamzawi, K. J. Kennedy and D. D. McLean, Water Sci. Technol., 1998, 38, 127-132.

19 Y. G. Xue, H. J. Liu, S. S. Chen, N. Dichtl, X. H. Dai and N. Li, Chem. Eng. J., 2015, 264, 174-180.

20 W. B. Han, Y. Z. Zhao and H. Chen, Procedia Environ. Sci., 2016, 35, 756-762.

21 J. M. Wang, C. P. Huang and H. E. Allen, Water Environ. Res., 2000, 72, 545-553.

22 S. C. Lenore, E. G. Arnold, D. E. Andrew and A. H. F. Mary, Standard Methods for the Examination of Water and
Wastewater, American Public Health Association, Washington (US), 21st edn, 2005.

23 F. J. Stevenson, Humus Chemistry: Genesis, Composition, Reactions, John Wiley \& Sons, Inc., New York, 1994.

24 R. S. Swift, Organic matter characterization, in methods of soil analysis, Part 3-chemical methods, Soil Science Society of America, Madison, WI, 1996.

25 A. Donoso-Bravo, S. Pérez-Elvira, E. Aymerich and F. FdzPolanco, Bioresour. Technol., 2011, 102, 660-666.

26 R. Dreywood, Ind. Eng. Chem. Res., 1946, 18, 199.

27 C. Bougrier, J. P. Delgenes and H. Carrere, Chem. Eng. J., 2008, 139, 236-244.

$28 \mathrm{~J}$. Kopp and K. B. Kopp, Theoretische Grundlagen zur Entwässerbarkeit von Schlämmen, Fachtagung der VSA Kommission ARA, 2009.

29 I. Angelidaki and W. Sanders, Rev. Environ. Sci. Bio/Technol., 2004, 3, 117-129.

30 A. Veeken and B. Hamelers, Bioresour. Technol., 1999, 69, 249-254.

31 D. L. Nelson and M. M. Cox, Principles of Biochemistry, W. H. Freeman and Company, New York, 6th edn, 2013. 